\title{
Verotoxin production among porcine strains of Escherichia coli and its association with oedema disease
}

\author{
MARGARET A. LINGGOOD and JULIE M. THOMPSON \\ Unilever Research, Colworth Laboratory, Colworth House, Sharnbrook, Bedford MK44 $1 L Q$
}

\begin{abstract}
Summary. Strains of Escherichia coli isolated from documented cases of disease in pigs and belonging to a wide range of pathogenic serotypes were tested for their ability to produce a heat labile verotoxin (VT). The strains isolated from oedema disease all produced VT, indicating that the cytotoxin detected by the vero-cell assay was identical to "oedema disease principle". Strains belonging to the serotypes associated with enterotoxic diarrhoea were $\mathrm{VT}^{-}$. Not all the strains belonging to the recognised oedema disease serotypes (O141:K85, O139:K82 and O138:K81) produced VT, but the $\mathrm{VT}^{-}$strains were not associated with outbreaks of clinical disease.
\end{abstract}

\section{Introduction}

Oedema disease attacks thriving pigs about one week after weaning, the major feature being progressive incoordination leading to partial or complete paralysis and death. Post-mortem examination shows oedema in various sites, particularly the stomach wall and the mesentery of the colon (Sojka, 1965). The Escherichia coli strains associated with the disease are confined to the intestinal tract and it has been assumed, therefore, that they produce a neurotoxin, "oedema disease principle", which is absorbed and gives rise to the pathological signs. The presence of this toxin has been demonstrated in "freeze-thaw" extracts of oedema disease strains; intravenous injection of these extracts into pigs can give rise to a condition that is very similar to natural oedema disease (Erskine et al., 1957; Clugston and Nielsen, 1974).

Because study of the pathogenesis of oedema disease has been seriously hampered by the lack of a convenient in-vitro assay system for toxin, reports that some oedema disease strains produce a factor cytopathic for vero cells assume an added significance (Dobrescu, 1983; Smith et al., 1983). Two $E$. coli "verotoxins" have already been identified, namely the "Shiga-like" toxin produced by many human enteropathogenic $E$. coli strains and the verotoxin produced by strains associated with diseases such as haemorrhagic enteritis and haemolytic uraemic syndrome (Konowalchuk et al., 1977; Scotland et al., 1980; O’Brien et al., $1983 a, b$;

Received 3 July 1986; revised version accepted 24 Feb. 1987.
Karmali et al., 1985), but the porcine verotoxin (VT) appears to be different from these.

Smith et al. (1983) reported that about $63 \%$ of porcine strains belonging to the four serotypes associated with post-weaning disease (diarrhoea or oedema disease) in pigs were $\mathrm{VT}^{+}$. They did not, however, distinguish between the two types of postweaning disease. We considered that further work was needed to clarify the role of VT in virulence. Accordingly we examined a large number of isolates from documented cases of $E$. coli disease in pigs to determine whether VT was specifically associated with either post-weaning diarrhoea or oedema disease.

\section{Materials and methods}

\section{Source of E. coli strains}

Most of the strains were obtained during the period 1978-1985 from farms in the UK. The diagnosis of $E$. coli disease was made by veterinary practitioners, and faecal swabs, or, occasionally post-mortem samples of intestinal contents, were sent to us for bacteriological examination. The samples came from both neonatal and weaned pigs, but all the $0141: \mathrm{K} 85$ and $0139: \mathrm{K} 82$ isolates analysed in detail in tables II and III came from weaned pigs between 5 and 8 weeks old. The samples were plated out on blood agar and a representative number of haemolytic and non-haemolytic $E$. coli colonies were then picked, subcultured, and serotyped.

Toxins prepared from Shigella dysenteriae type 1 and from two human $E$. coli strains were included for comparison. The human $E$. coli strains belonged to serotypes $\mathrm{O} 26: \mathrm{K} 60: \mathrm{H} 11$ and $\mathrm{O} 157: \mathrm{H} 7$ and had been 
isolated from cases of diarrhoea and haemolytic uraemic syndrome respectively.

\section{Antitoxic sera}

Rabbits were immunised subcutaneously with cell-free VT preparations (culture supernates, see below) with Freund's complete adjuvant (Difco) for the first injection, and with Freund's incomplete adjuvant (Difco) for the second injection given 4 weeks later. The animals were bled 2 weeks after the second injection.

\section{Toxin assays}

Supernates of cultures grown in Mundell's medium (Ristaino et al., 1983) were tested for VT, and also for the heat stable (STa) and heat labile (LT) toxins. VT was assayed by the vero-cell method of Konowalchuk et al. (1977), before and after heat treatment at $70^{\circ} \mathrm{C}$ for 30 min. LT was assayed by ELISA (Svennerholm and Holmgren, 1978) and STa by the suckling-mouse test (Dean et al., 1972). In addition, LT assays were performed on cell lysates.

\section{Verotoxin neutralisation tests}

Toxin preparations were serially diluted and an endpoint titre was determined, i.e., the highest dilution giving a positive result in the assay. Doubling dilutions of the antisera were made in microtitration plates and an equal volume of diluted verotoxin was added to give a toxin concentration equivalent to the end-point titre. The plates were incubated at $37^{\circ} \mathrm{C}$ for $60 \mathrm{~min}$ and then $50 \mu \mathrm{l}$ from each well assayed for verotoxic activity.

\section{Results}

\section{Identification of three verotoxins}

Neutralisation tests indicated two immunologically different verotoxins in the human $E$. coli cultures, the $\mathrm{O} 26$ verotoxin being similar to Shiga toxin. The porcine verotoxin was not neutralised by antisera to either of the human strain verotoxins.

The human verotoxins were inactivated by heat treatment at $80^{\circ} \mathrm{C}$ but were stable at $70^{\circ} \mathrm{C}$. The verotoxins produced by all the porcine strains mentioned in this report were inactivated by heat treatment at $70^{\circ} \mathrm{C}$.

\section{Occurrence of porcine verotoxin}

The association of the porcine (heat labile) verotoxin with serotype is shown in table I. Strains were divided into two groups. Group A comprised those serotypes encountered in colibacillary diarrhoea particularly in neonatal piglets. Group B
Table I. Verotoxin production among porcine strains of E. coli

\begin{tabular}{lcc} 
Serotype & $\begin{array}{c}\text { Number of strains } \\
\text { tested }\end{array}$ & $\begin{array}{c}\text { Number of } \mathrm{VT}^{+} \\
\text {strains }\end{array}$ \\
\hline Group A* & 10 & 0 \\
O149:K91, K88ac & 2 & 2 \\
O141:K85, K88ab & 4 & 0 \\
O8:K87, K88ab/ac & 1 & 0 \\
O8:K85, K99 & 6 & 0 \\
O157:K'V17', K88ac & 3 & 0 \\
O157:K'V17' & 2 & 0 \\
O45:K'E65', K88ac & 2 & 0 \\
O138:K81, K88ac & 1 & 0 \\
O147:K89, K88ac & & \\
Group B* & 30 & 23 \\
O141:K85 & 8 & 6 \\
O139:K82 & 11 & 3 \\
O138:K81 & 17 & 6 \\
'Untypables' & & \\
\hline
\end{tabular}

* The group A serotypes are usually associated with diarrhoea,
particularly in neonatal pigs, and the group B serotypes with
oedema disease or diarrhoea, particularly in weaned pigs.

contained serotypes more often found in weaned pigs and either associated only with oedema disease (O139:K82) or with both oedema disease and diarrhoea (O141:K85 and O138:K81) (Sojka, 1973). With the exception of the two $0141: K 85$, $\mathrm{K} 88 \mathrm{ab}$ strains, the group A strains were $\mathrm{VT}^{-}$, but two-thirds of the group B strains were $\mathrm{VT}^{+}$(table I). Among the group of "untypables" were six strains isolated by J. E. T. Jones (Royal Veterinary College) from post-weaning pigs with "haemorrhagic enteritis", one of which produced VT. The remaining 11 untypable strains were part of the mixed faecal flora of healthy pigs; two of them produced VT.

The association of porcine verotoxin with disease is shown in tables II and III. It will be seen that $\mathrm{VT}^{+} E$. coli was present in all pigs suffering from oedema disease, but when the same serotypes were isolated from healthy pigs, or pigs with postweaning diarrhoea ("scours"), they were usually $\mathrm{VT}^{-}$. Two of three $\mathrm{VT}^{-} \mathrm{O} 141: \mathrm{K} 85$ strains isolated from post-weaning diarrhoea were STa producers.

\section{Discussion}

Approximately $67 \%$ of $E$. coli strains belonging to serotypes associated with two serious postweaning syndromes in pigs, diarrhoea and oedema disease, produced verotoxin. This "porcine verotoxin" could be clearly differentiated from two 
Table II. Details of O141 : K85 isolates

\begin{tabular}{|c|c|c|c|c|c|c|}
\hline \multirow[b]{2}{*}{ Farm } & \multirow{2}{*}{$\begin{array}{l}\text { Year of } \\
\text { isolation }\end{array}$} & \multirow{2}{*}{$\begin{array}{l}\text { Number of } \\
\text { isolates } \\
\text { tested }\end{array}$} & \multirow{2}{*}{ Syndrome } & \multicolumn{3}{|c|}{ Toxins detected } \\
\hline & & & & VT & LT & STa \\
\hline $\mathrm{Ba}$ & 1979 & 1 & OD & + & - & - \\
\hline St & 1979 & 2 & OD & + & - & - \\
\hline $\mathbf{N}$ & 1979 & 1 & OD & + & - & - \\
\hline $\mathrm{T}$ & 1980 & 2 & OD & + & - & - \\
\hline $\mathbf{M}$ & 1982 & 4 & OD & + & - & - \\
\hline $\mathrm{G}$ & $1983-1984$ & 9 & OD & + & - & - \\
\hline $\mathrm{G}$ & $1983-1984$ & 1 & OD & - & + & + \\
\hline Nut & 1985 & 3 & OD & + & - & - \\
\hline $\mathrm{F}$ & 1979 & 1 & Scours & - & - & + \\
\hline $\mathrm{D}$ & 1979 & 2 & Scours & - & - & - \\
\hline $\mathrm{Sp}$ & 1980 & 1 & Scours & - & - & + \\
\hline Tw & 1978 & 1 & Healthy & + & - & - \\
\hline $\mathrm{Be}$ & 1979 & 1 & Healthy & - & - & - \\
\hline $\mathrm{E}$ & 1979 & 1 & Healthy & - & - & - \\
\hline
\end{tabular}

$\mathrm{OD}=$ clinical oedema disease

Scours = diarrhoea with $0141:$ K85 present in almost pure culture.

Healthy $=$ no $E$. coli disease ; faecal swabs yielded very heterogeneous cultures.

"human verotoxins" on the basis of antigenic crossreactivity and heat stability. Previous studies had revealed the general association of porcine VT with serotype, but we found that an analysis of the strains based on the clinical signs in the infected pigs, rather than simply on serotype, provided much stronger evidence for the role of verotoxin in virulence.

Verotoxin-producing $E$. coli strains were isolated from all cases of oedema disease examined in this laboratory over a 7-year period, but when the same

Table III. Details of O139: K82 isolates

\begin{tabular}{lcllll}
\hline & & & \multicolumn{3}{c}{ Toxins detected } \\
\cline { 4 - 6 } Farm & $\begin{array}{c}\text { Year of } \\
\text { isolation }\end{array}$ & Syndrome & VT & LT & STa \\
\hline K & 1962 & OD & + & - & - \\
Sw & 1978 & OD & + & - & - \\
C & 1979 & OD & + & - & - \\
We & 1979 & Healthy A & - & - & - \\
J & 1980 & Healthy A & - & - & - \\
Th & 1978 & Healthy B & - & - & - \\
Spex & 1979 & Healthy B & + & - & - \\
R & 1979 & Healthy B & - & - & - \\
\hline
\end{tabular}

$\mathrm{OD}=$ clinical oedema disease.

Healthy $\mathrm{A}=$ strain present in almost pure culture in faeces but no OD.

Healthy $\mathrm{B}=$ no $E$. coli disease; faecal swabs yielded very heterogeneous cultures. serotypes were isolated from healthy pigs, or pigs suffering from post-weaning diarrhoea, they were usually $\mathrm{VT}^{-}$.

It was possible to divide the $0141: \mathrm{K} 85$ strains into three "types", as follows. (i) Strains producing VT but not enterotoxin, that had the potential to produce oedema disease but not diarrhoea and were isolated from all cases of oedema disease. (ii) Strains producing enterotoxin but not VT, which were isolated from animals with diarrhoea but without oedema disease. (The diarrhoea observed on Farm $\mathrm{D}$ may have been due to another agent such as rotavirus, or the strain may have been producing $\mathrm{STb}$, which is not detected in the infant mouse assay.) (iii) Strains that did not produce VT or enterotoxin and were probably non-pathogenic; they were found in the mixed faecal flora of healthy pigs.

Strains of the O139:K82 serotype are nonenterotoxigenic and are associated with oedema disease but not diarrhoea in weaned pigs (Sojka, 1973). They predominated in oedema disease in the UK in the 1950s and 1960s (Sojka et al., 1960; Sojka, 1965), but in our survey all cases of clinical oedema disease in the UK between 1978 and 1985 were associated with $\mathrm{O} 141: \mathrm{K} 85$ strains. O139:K82 strains were usually found as minor constituents of the mixed faecal flora of healthy animals. Three strains of $0139: \mathrm{K} 82$ isolated from cases of oedema disease are referred to in table III-one isolated in the UK in 1962, one (Sw/78) in Switzerland, and the other (C/79) in Spain. The O139:K82 serotype may have declined in importance as an oedema disease pathogen in the UK, but it is still significant in other parts of Europe.

The three $\mathrm{O} 139$ strains isolated from diagnosed cases of oedema disease were VT producers. When only VT ${ }^{-} \mathrm{O} 139$ strains were isolated there were no signs of oedema disease on the farms concerned, even on Farms We and $\mathbf{J}$ where the strains were present in almost pure culture in faecal swabs. According to the veterinarian in attendance, Farm $\mathbf{J}$ had been affected by oedema disease 15 years earlier, but it had disappeared. Possibly the disappearance of the disease coincided with the loss of the ability of the strain to produce VT, even though it could still colonise the pig intestine.

Both the $0141: \mathrm{K} 85, \mathrm{~K} 88 \mathrm{ab}$ strains in the survey produced VT and were the only examples of strains that produced verotoxin and classical enterotoxins. Natural loss of the K88 and Hly plasmids by these strains did not affect their ability to produce VT. One of them was the O141:K85, K88ab strain used by Smith and Linggood (1971) to infect pigs. It was used in repeated experiments and found to produce 
severe diarrhoea in both neonatal and weaned pigs. Signs of oedema disease were never observed. One possible explanation is that any VT produced in vivo was flushed out by the diarrhoea induced by the enterotoxins, and therefore was not absorbed.

Our major observation was that $\mathrm{VT}^{+} E$. coli were isolated from all cases of oedema disease. This strongly suggests that the cytotoxin measured by the vero cell assay is identical to the oedema disease principle responsible for the clinical signs of oedema

\section{REFERENCES}

Clugston R E, Nielsen N O 1974 Experimental edema disease of swine ( $E$. coli enterotoxaemia). 1. Detection and preparation of an active principle. Canadian Journal of Comparative Medicine 38 : 22-28.

Dean A G, Ching Y-C, Williams R G, Harden L B 1972 Test for Escherichia coli enterotoxin using infant mice: application in a study of diarrhea in children in Honolulu. Journal of Infectious Diseases 125: 407-411.

Dobrescu L 1983 New biological effect of edema disease principle (Escherichia coli-neurotoxin) and its use as an invitro assay for this toxin. American Journal of Veterinary Research 44: 31-34.

Erskine R G, Sojka W J, Lloyd M K 1957 The experimental reproduction of a syndrome indistinguishable from oedema disease. Veterinary Record 69 : 301-303.

Karmali M A, Petric M, Lim C, Fleming P C, Arbus G S, Lior H 1985 The association between idiopathic hemolytic uremic syndrome and infection by verotoxin-producing Escherichia coli. Journal of Infectious Diseases 151: 775-782.

Konowalchuk J, Speirs J I, Stavric S 1977 Vero response to a cytotoxin of Escherichia coli. Infection and Immunity 18: 775-779.

O'Brien A D, Lively T A, Chang T W, Gorbach S L 1983a Purification of Shigella dysenteriae 1 (Shiga)-like toxin from Escherichia coli O157:H7 strain associated with haemorrhagic colitis. Lancet 2: 573.

O'Brien A D, Lively T A, Chen M E, Rothman S W, Formal S B 1983b Escherichia coli O157:H7 strains associated with disease. It should also be noted that although the serotype of a strain may give some indication of its potential to cause oedema disease, not all strains belonging to "oedema disease serotypes" produce VT ("oedema disease principle"). Such VT" ${ }^{-}$strains were not associated with clinical outbreaks of the disease.

We are grateful to J. A. Blades and J. Dean for help with the collection and typing of strains.

haemorrhagic colitis in the United States produce a Shigella dysenteriae 1 (Shiga)-like cytotoxin. Lancet 1: 702.

Ristaino P A, Levine M M, Young C R 1983 Improved GM1enzyme linked immunosorbent assay for detection of Escherichia coli heat-labile enterotoxin. Journal of Clinical Microbiology 18: 808-815.

Scotland S M, Day N P, Rowe B 1980 Production of a cytotoxin affecting Vero cells by strains of Escherichia coli belonging to traditional enteropathogenic serogroups. FEMS Microbiology Letters, 7: 15-17.

Smith, H W, Green P, Parsell Z 1983 Vero cell toxins in Escherichia coli and related bacteria: transfer by phage and conjugation and toxic action in laboratory animals, chickens and pigs. Journal of General Microbiology 129: 3121-3137.

Smith H W, Linggood M A 1971 Observations on the pathogenic properties of the K88, Hly and Ent plasmids of Escherichia coli with particular reference to porcine diarrhoea. Journal of Medical Microbiology $4: 467-485$.

Sojka W J 1965 Escherichia coli in domestic animals and poultry. Review series no. 7 of the Commonwealth Bureau of Animal Health, Farnham Royal.

Sojka W J 1973 Enteropathogenic Escherichia coli in man and farm animals. Canadian Institute of Food Science and Technology Journal 6: 52-63.

Sojka W J, Lloyd M K, Sweeney E J 1960 Escherichia coli serotypes associated with certain pig diseases. Research in Veterinary Science 1: 17-27.

Svennerholm A M, Holmgren, J 1978 Identification of Escherichia coli heat-labile enterotoxin by means of a ganglioside immunosorbent assay (GM1-ELISA) procedure. Current Microbiology 1 : 19-23. 